British Journal of Psychiatry (1996), 169, 665-673

\title{
Correspondence
}

Contents: Recovered memories/Genomics/Depression and the safety of antidepressants/Incidence of mental disorder/Women and psychiatry/ Melancholia and response to ECT/Urine screening for drugs and trazodone/Costing community care/ Cytochromes and psychotropic drug interactions/ White matter lesions in depression and Alzheimer's disease/ECT with clozapine: efficacy and safety/ Childhood autism in Japan/Nefazodone-induced spontaneous ejaculation.

\section{Recovered memories}

SIR: Brewin (1996) claims that opinion appears to be "shifting rather rapidly in response to studies published in the last few years" against the view that claims of repressed memories recovered in therapy are not supported by credible scientific data. He gives no evidence for his own claim, and no survey of academic opinion exists at the moment in any country, but Chodoff (1996) reviewing Ford (1996) says the following: "In his chapter on false memory, he reviews recent insights into the vagaries of memory and takes the position, now becoming almost standard in the psychiatric community, that the evidence for many so-called recovered memories of early sexual abuse is frighteningly weak.

The Canadian Psychiatric Association (Blackshaw et al, 1996) recently issued a position statement on this subject, which includes the following: "... if memories of events have not been revisited and cognitively rehearsed ... [until] ... some years later, it is not clear that such memories can be accessible, or be reliable." This statement recognises the theoretical possibility that reports of recovered memory may be true and then adds, ". . . but great caution should be exercised before acceptance in the absence of solid corroboration." The theoretical possibility is acknowledged, but the practical conclusion emphasised. In the United States, the Prudential National Insurance Company will not now insure a mental health practitioner, if among other things she or he uses "... hypnotherapy to assist clients in recovering failed or repressed memories of possible abuse."
Several of the references on which Brewin relies to prove recovery of memory come from clinics with an outspoken political agenda, such as Herman (1992) where evidence was gathered among patients who had joined groups of 'survivors' while they were in therapy and many simply claimed that another family member agreed with them. Pope \& Hudson (1995) demonstrated that the evidence from such sources was worthless. The only source on which Brewin relies and in which the presence of memories was examined in a true follow-up study is Williams $(1994 ; 1995)$, and that at first did not demonstrate recovery of memories, but only loss of them. Twelve women were identified post hoc who claimed to have lost their memories at one time. The meaning of this is uncertain, and five of the 12 claimed memories from an age (two or three years old) that is inherently improbable. Schooler's (1994) case is suggestive, but Schooler admits the evidence is indirect. Loftus et al (1994) clearly did not agree that their work supported the notion of recovery of memory in the sense that Brewin is advocating. As Pope \& Hudson (1995) indicate, considering the frequency of the claims of recovered memory, the dearth of proven recovered memory is a striking discrepancy. The population base-rate for the coincidence of true sexual abuse and memory for it returning after a long interval of forgetting, ignoring, not attending to or repressing the events, is apparently very low, if not unmeasurable.

It is not surprising, however, as knowledge of the problems of this type of treatment spreads that reports from treatment settings decline and claims increase that memories arose outside treatment. As with multiple personality disorder, so much is put about in 'survivors' groups and the general media that anyone can get the idea or the stimulus to develop a supposed memory. It is now recognised, by professional societies and insurance companies alike, that recovered memory therapy is financially and socially hazardous to those who wish to produce it or claim its fruits, one of which is the ability to accuse. Therapists are accordingly moving away from acknowledging it. I have seen this course of events in six criminal trials in English-speaking Canada, in which complainants and their therapists 
back-pedalled away from acknowledging that the discovery occurred in therapy. One mother of a complainant said she had always known, but had "put it on the back burner." Another, whose counsellors were recorded as pursuing the theory that she had experienced childhood abuse (initially with some difficulty because she was fond of her kindly father), developed her first ideas on a day in between therapy sessions. About 1000 hours of therapy later, she had an extensive belief system, including at least as many occasions of abuse as hours of treatment. A colleague in Quebec has observed the same outcome with rightful acquittals in six other trials. What juries and judges in Canada have just learned, Dr Brewin wishes us to unlearn.

BREWIN, C. R. (1996) Scientific status of recovered memories. British Journal of Psychiatry, 169, 131-134.

Blackshaw, S., Chandarana, P., Garneau, Y. et al, for the Canadian Psychiatric Association (1996) Position Statement on adult recovered memories of childhood sexual abuse. Canadian Journal of Psychiatry, 41, 305-306.

CHODOFF, P. (1996) Lies. Journal of American Medical Association, 276, 76-77.

Ford, C. V. (1996) Lies!, Lies!!, Lies!!! The Psychology of Deceit. Washington, DC: American Psychiatric Press.

Herman, J. L. (1992) Trauma and Recovery. New York, NY: Basic Books.

Loftus, E. F., Polonsky, S. \& Fullilove, M. (1994) Memories of childhood sexual abuse: remembering and repressing. Psychology of Women Quarterly, 18, 67-84.

POPE, H. G. \& HUDSON, J. I. (1995) Can memories of childhood sexual abuse be repressed? Psychological Medicine, 25, 121-126.

SCHOOLER, J. W. (1994) Seeking the core: the issues and evidence surrounding recovered accounts of sexual trauma. Consciousness and Cognition, 3, 465-469.

WILLiAms, L. M. (1994) Recall of childhood trauma: a prospective study of women's memories of childhood sexual abuse. Journal of Consulting and Clinical Psychology, 62, 1167-1176.

WrlunMs, L. M. (1995) Recovered memories of abuse in women with documented child sexual victimization histories. Journal of Traumatic Stress, 8, 649-673.

London Psychiatric Hospital

University of Western Ontario

London, Ontario N6A 4H1, Canada

H. MerSKey

\section{Genomics}

SIR: Neuropsychiatry continues to leave me dumbfounded at its lack of connectedness with human experience. This 'cut-offness' was clearly demonstrated in Farmer \& Owen's article (1996). First they sell the latest false dream. They conclude that "there is little doubt" that the genetic aetiology of "common familial disorders including the major psychiatric disorders" will be discovered, and that this knowledge "will radically alter clinical practice." A brief review of the history of psy- chiatry reveals how many previous false dawns there have been: hormone, pharmacotherapy, cognitive-behavioural therapy, neuroimaging, molecular biochemistry. Farmer \& Owen point out the huge ethical dilemmas, not just about the potential misuse but the history of actual misuse of genetic notions of human history, culture and difference. This history and potential should not surprise us. The sense of omnipotence that accompanies such beliefs can never be far from the surface. Genetic science is saying, "I understand what the ideal gene pool should look like, I know therefore what the perfect human being should consist of." What parents, if told their baby had genes that put them at risk for a psychiatric disorder, would not want them changed? Farmer \& Owen also suggest that knowledge of the genetics of psychiatric disorders could lead to pre-symptomatic testing. Some of their suggestions are simply laughable. "Advice can be given to individuals with high genetic loading for these disorders regarding exposure to environmental precipitants such as use of street drugs." Other suggestions terrified me. Presymptomatic identification of high-risk individuals is suggested. Imagine this: you are told that you have a high risk for schizophrenia. The warning signs have much to do with your thoughts. Suppose now that you get angry at someone, so angry that your thoughts are erratic, destructive and irrational. Will you question whether this is the first signs you were warned about? Worse still, will others now interpret this as a sign that you are developing the illness? (Oh dear, we were warned about this, we'd better get him down to the doctors, he has no insight.) Such a risk-factor culture is also an invitation for a spurious identification, a kind of self-fulfilling prophecy.

FARMer, A. \& OWEN, M. J. (1996) Genomics: the next psychiatric revolution? British Journal of Psychiatry, 169, 135-138.

Lower Clapton Health Centre

S. Trrma

36 Lower Clapton Road

London E5 OPQ

SR: Farmer \& Owen (1996) gave a subtle description of the various reactions of psychiatrists with respect to the expansion of genetics in recent years. As do most articles addressing the developments in the combined field of psychiatry and genetics, those authors emphasise the detection, comprehension and prevention of the major entities in adult and geriatric psychiatry, and the ethical and psychological problems related to genetic counselling in the context of 